\title{
Clausenidin induces caspase-dependent apoptosis in colon cancer
}

\author{
Peter M. Waziri ${ }^{1,2^{*}}$, Rasedee Abdullah³ ${ }^{3}$, Swee Keong Yeap ${ }^{4}$, Abdul Rahman Omar ${ }^{4}$, Nur Kartinee Kassim \\ Ibrahim Malami ${ }^{1}$, Chee Wun How ${ }^{4}$, Imaobong Christopher Etti ${ }^{1}$ and Mary Ladidi Abu ${ }^{6}$
}

\begin{abstract}
Background: Clausena excavata Burm.f. is a shrub traditionally used to treat cancer patients in Asia. The main bioactive chemical components of the plant are alkaloids and coumarins. In this study, we isolated clausenidin from the roots of $C$. excavata to determine its apoptotic effect on the colon cancer (HT-29) cell line.

Method: We examined the effect of clausenidin on cell viability, ROS generation, DNA fragmentation, mitochondrial membrane potential in HT-29 cells. Ultrastructural analysis was conducted for morphological evidence of apoptosis in the treated HT-29 cells. In addition, we also evaluated the effect of clausenidin treatment on the expression of caspase 3 and 9 genes and proteins in HT-29 cells.

Result: Clausenidin induced a G0/G1 cell cycle arrest in HT-29 cells with significant $(p<0.05)$ dose-dependent increase in apoptotic cell population. The DNA fragmentation assay also showed apoptotic features in the clausenidin-treated HT-29 cells. Clausenidin treatment had caused significant $(p<0.05)$ increases in the expression of caspase 9 protein and gene in HT-29 cells and mitochondrial ROS and mitochondrial membrane depolarization. The results suggest the involvement of the mitochondria in the caspase-dependent apoptosis in clausenidin-treated colon cancer cells.
\end{abstract}

Conclusion: Clausenidin induces a caspase-dependent apoptosis in colon cancers through the stimulation of the mitochondria. The study demonstrates the potential of clausenidin for use in the treatment of colon cancers.

Keywords: Clausenidin, Apoptosis, Colon cancer, MMP, Caspase 9, bcl 2, bax

\section{Background}

Colon cancer is the second leading cause of cancer deaths worldwide accounting for over 1.4 million new cases each year [1,2]. Colon cancers are rising at an alarming rate in countries where very few treatment options are available. It is projected that from 2015 to 2030 the incidence of the disease in developing countries will increase by as much as $60 \%$ [3] and will present great challenges to the management of the cancer. It has been shown that there are close associations between molecular signaling, energy generation, and proliferation of tumors $[4,5]$. Since these molecular mechanisms can

\footnotetext{
* Correspondence: petermwaziri@gmail.com

${ }^{1}$ MAKNA Cancer Research Laboratory, Institute of Bioscience, University Putra Malaysia, Serdang, Selangor, Malaysia

${ }^{2}$ Department of Biochemistry, Kaduna State University, Main Campus, PMB

2336 Kaduna, Nigeria

Full list of author information is available at the end of the article
}

promote tumor cell proliferation, they are usually the targets of cancer chemotherapies [6].

Cancer chemotherapeutic agents are screened and selected based on their potentials to induce apoptosis [7]. Apoptosis is an integral cell death program characterized by DNA fragmentation as well as loss of mitochondrial membrane integrity [8]. This mode of cell death is driven by caspases and proceeds via the extrinsic or intrinsic pathways. The intrinsic pathway of apoptosis is tightly coordinated by the mitochondria via the activation of caspase $9[9,10]$. Because of the integral role it plays, caspase 9 is often referred to as gatekeeper of the mitochondrial pathway [11]. Upon activation, caspase 9 activates caspase 3 , whose action leads to the execution of apoptosis. Apoptotic strategies to destroy tumor cells may involve direct stimulation of pro-apoptotic molecules, modulation of anti-apoptotic proteins or induction of tumor suppressor function [12]. The functions of 
caspase 9 gene and promoter help to drive apoptosis to ensure that abnormal and senescent cells are removed from the body [13]. A comparison between the normal and tumor cells of colorectal cancer patients had shown decreased expression of caspase 9 in tumors [14]. In situations where tumors arise due to altered gene expression, treatments can be targeted towards improving the expression of the gene because the activation or inhibition of certain genes could stimulate apoptosis and alter the kinetics of tumor growth [15].

Clausenidin (Fig. 1) is a natural pyranocoumarin from Clausenidin excavata Burm. $f$., a wild shrub of the Rutaceae family predominantly used in Asian folk medicine $[16,17]$. The plant has been used locally to treat cold, dermatopathy, snake bite, malaria, HIV and abdominal pains $[18,19]$. In Thailand, it has been reported that Clausena excavata is traditionally used in the treatment of cancers [17]. In a recent study, Su et al. [20] isolated four pyranocoumarins from $C$. excavata and screened their cytotoxic potentials in cancer cells. The study revealed that the pyranocoumarins are good modulators of tumor cell death. In another study dentatin isolated from $C$. excavata was shown to increase the expression of caspase 9 in MCF-7 cells [21]. In our laboratory we observed that the expression of caspase 9 increases in clausenidin-treated hepG2 cells (Unpublished report). However, the underlying mechanisms by which clausenidin induces apoptosis has not been fully resolved. The current study describes for the first time, some molecular mechanisms involved in clausenidin-induced cell death in a colon cancer cell line. The study also provides insights on caspase-dependent apoptosis triggered by clausenidin in colon cancers.

\section{Methods}

\section{Extraction and isolation of compound}

Fresh roots of Clausena excavata Burm.f. were collected from the Agricultural Park, Institute of Bioscience,

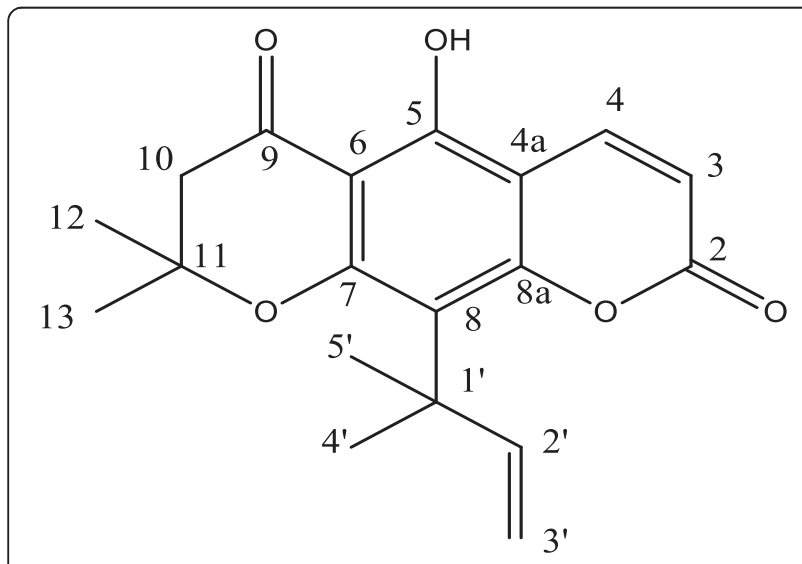

Fig. 1 Structure of Clausenidin
University Putra Malaysia. The identification of the plant material was done by Dr Shamsul Khamis of the Institute and a voucher specimen was deposited in the herbarium (2991/16). The roots (2 kg) were air-dried for 2 weeks, ground to fine powder and used for the extraction process. The extraction of clausenidin was performed by soaking the fine powder in $1 \mathrm{~L}$ chloroform for 3 days followed by filtration through $0.45 \mu \mathrm{m}$ filter paper (Sigma Aldrich, US) to collect the extract. The extract was subjected to glass column chromatography through silica gel, as described by Arbab et al. [21], to obtain pure clausenidin crystals $(524 \mathrm{mg}$ ). The clausenidin crystals were subjected to mass spectrometry (Shidmadzu GCMS-QP5050A) while the melting point was determined using a Barnstead melting point apparatus $[16,18]$.

\section{Cell viability assay}

Human colon cancer (HT-29) cells were obtained from American Type Culture Collection (ATCC, Va, USA) and doxorubicin from EMD Millipore, US. The cells were maintained in DMEM medium supplemented with $10 \%$ Fetal Bovine Serum (FBS). About 5000 cells were seeded into each well of a 96 well plate and incubated for $24 \mathrm{~h}$. Treatment was done with increasing concentrations of clausenidin and doxorubicin (positive control). Negative control cells were treated with $0.1 \%(\mathrm{v} / \mathrm{v})$ DMSO. After $72 \mathrm{~h}$, MTT $(5 \mathrm{mg} / \mathrm{mL})$ was added for the viability assay as described previously by Syam [22]. Results obtained were expressed as percentage cytotoxicity after $72 \mathrm{~h}$ exposure to test agents.

\section{Morphological assessment of apoptotic cells by acridine orange $(\mathrm{AO})$ and propidium iodide (PI) double staining} Clausenidin induced cell death in HT-29 cells was monitored using acridine orange $(\mathrm{AO})$ and propidium iodide (PI) double-staining according to standard procedures. Cells were seeded in a 6 well plate $\left(10^{5}\right.$ cells/well $)$ and incubated overnight. The cells were treated for $24 \mathrm{~h}$ with increasing concentrations of clausenidin after which the cells were harvested and washed with PBS. The cells were centrifuged at $1000 \mathrm{~g}$ for $5 \mathrm{~min}$ and the supernatant was discarded. The washing procedure was repeated twice to remove traces of media from the cells. Ten microliters $(10 \mu \mathrm{l})$ of fluorescent dyes containing AO $(10 \mathrm{mg} / \mathrm{mL}$ and PI $(10 \mathrm{mg} / \mathrm{mL})$ were added into the cellular pellet at equal volumes. Freshly stained cell suspension was dropped on a glass slide and covered with a cover slip. Slides were observed under fluorescent microscope within $30 \mathrm{~min}$ before the fluorescence fades.

\section{Transmission electron microscopy}

To prepare the cells for transmission electron microscopy (TEM), HT-29 cells were seeded at a density of $10^{6}$ cells/T- 
$25 \mathrm{ml}$ flask and incubated overnight. The cells were then treated with the $\mathrm{IC}_{50}$ of clausenidin $(13.8 \mu \mathrm{g} / \mathrm{mL})$ in a time dependent manner while the negative control cells were treated with $0.1 \%(\mathrm{v} / \mathrm{v})$ DMSO. After treatment, cells were harvested and washed with PBS before successive fixing with $4 \%$ glutaraldehyde for $24 \mathrm{~h}$ and $1 \%$ osmium tetraoxide at $4{ }^{\circ} \mathrm{C}$ for $2 \mathrm{~h}$. After each fixing, washing was done three times with $0.1 \mathrm{M}$ sodium cacodylate buffer. Dehydration of the cells was carried out with increasing concentrations of acetone $(30-99.9 \%)$. Further processing of cut sections was done using the method described by Tan et al. [23]. The sections were stained with uranyl acetate and viewed under the Hitachi $\mathrm{H}-7100$ electron microscope.

\section{ROS assay}

The ROS assay was performed to measure the intracellular ROS production from the mitochondria of clausenidin-treated HT-29 cells. Briefly, cells were seeded at a density of $2 \times 10^{5}$ cells/well in a 6 well plate and incubated overnight. The cells were then treated with clausenidin $(13.8 \mu \mathrm{g} / \mathrm{mL})$ at increasing time period and harvested for the ROS assay, which was performed using the Total ROS assay kit (ebioscience Inc, Affymetrix) according to manufacturer's protocol. The assay results were analyzed on a flow cytometer (BD FACS, Calibur).

\section{DNA fragmentation analysis}

The HT-29 cells were seeded at a density of $10^{6}$ cells $/ \mathrm{ml}$ in culture flask and incubated overnight. The cells were then treated with clausenidin $(13.8 \mu \mathrm{g} / \mathrm{mL})$ for $12 \mathrm{~h}$ and $24 \mathrm{~h}$ respectively after which the cells were harvested and DNA was extracted using the suicide-track ${ }^{\mathrm{TM}}$ DNA Ladder Isolation kit (Calbiochem, USA) according to the manufacturer's protocol. The principle involves detection of the cytoplasmic histone-associated DNA fragments (mononucleosome and oligo- nucleosomes) formed during apoptosis. After extraction, the concentration and purity of the DNA was confirmed on a nanodrop spectrophotometer. The extracted DNA samples were run on a $1.5 \%$ agarose gel in Tris-acetic acidEDTA buffer and gel image was captured on GelDoc (Biorad, USA). HL-60 cells induced to undergo apoptosis with Actinomycin D, supplied with the assay kit was used as positive control.

\section{Cell cycle analysis by flow cytometry}

The HT29 cells were seeded at a concentration of $10^{6}$ cells/T-25 ml flask in RPMI media and incubated overnight. The cells were then treated with clausenidin $(13.8 \mu \mathrm{g} / \mathrm{mL})$ at an increasing time period while the negative control cells were treated with $0.1 \%(\mathrm{v} / \mathrm{v})$ DMSO. After treatment, cells were harvested and washed with PBS. The cell cycle assay was performed using BD cell cycle reagent (CycleTest ${ }^{\mathrm{Tm}}$ Plus DNA reagent kit, Becton Dickinson, Belgium) according to manufacturer's protocol and the result was analyzed on a flow cytometer (BD FACS, Calibur) using the BD cell quest pro software.

\section{Annexin V assay}

HT-29 cells were seeded at a concentration of $2 \times$ $10^{5}$ cells/T-25 flask in RPMI media and incubated overnight. The cells were then treated with increasing concentrations of clausenidin while the negative control was treated with $0.1 \%(\mathrm{v} / \mathrm{v})$ DMSO. Cells were harvested after treatment and washed with PBS. Annexin V assay was then carried out using FITC annexin V assay kit (BD Pharmingen, USA) following the manufacturer's protocol and the result was analyzed on a flow cytometer.

\section{Mitochondrial membrane potential (MMP) assay}

Mitochondrial membrane potential assay was performed to determine the polarization/depolarization of the mitochondrial membrane using the JC-1 dye. HT29 cells were seeded at a density of $5 \times 10^{5}$ cells/well in a 6 well plate, incubated overnight and then treated with increasing concentrations of clausenidin for a period of $24 \mathrm{~h}$. The negative control cells were treated with $0.1 \%(\mathrm{v} / \mathrm{v})$ DMSO. The assay was performed using the $\mathrm{BD}^{\mathrm{m}}$ Mitoscreen kit (BDbiosciences, US) according to manufacturer's instruction. The results were analyzed on a flow cytometer (BD FACS, Calibur) using the BD cell quest pro software.

\section{Caspases 3 and 9 assays}

Caspases 3 and 9 activity were determined using the colorimetric method (Genescript Colorimetric Assay kit, USA). Cells were initially seeded in a 6 well plate at a density of $10^{6}$ cells/well overnight. The cells were treated for $24 \mathrm{~h}$ with increasing concentrations of clausenidin and then cleaved Caspases 3 and 9 assays were performed respectively according manufacturer's protocol. Negative control cells were treated with $0.1 \%(\mathrm{v} / \mathrm{v})$ DMSO. After the completion of reaction, the plates were read on microplate reader at $405 \mathrm{~nm}$.

\section{RNA isolation}

RNA extraction was basically done to study the expression of the genes and get possible insights into the mechanism of apoptosis induced by clausenidin. After treatment of cells with clausenidin and $0.1 \%$ DMSO (for negative control) in a 6 well plate $\left(10^{6}\right.$ cells/well $)$, the cells were harvested with trypsin and washed with PBS. The RNA was extracted using the Total RNA extraction kit (GF-1 TRE kit, Vivantis technologies) according to the manufacturer's protocol. The extracted RNA was quantified using a nanodrop spectrophotometer at $260 \mathrm{~nm}$. 


\section{RT-qPCR}

The reverse transcriptase quantitative PCR (RT-qPCR) was carried out according to the GenomeLab GeXP Kit (Beckman Coulter, USA) protocol, in an XP Thermal Cycler (Bioer Technology, Germany). PCR products were finally analyzed on the GeXP genetic analysis system and the results normalized on express Profiler software based on the manufacturer's instructions. The primers for the genes of interest and housekeeping gene (Table 1) were designed on NCBI website and purchased from Biosune (Shanghai, China), while the internal control (Kanr) was supplied by Beckman Coulter (USA).

\section{Statistical analysis}

Data were presented as mean \pm standard deviation. One way Analysis of Variance (ANOVA) on SPSS 22 software (SPSS Inc, Chicago IL, USA) was used to assess the level of significance between means at $95 \%$ confidence interval $(p<0.05)$.

\section{Results}

\section{Cell viability and cytotoxicity assay}

The cell viability assay was performed to evaluate the percentage (\%) cytotoxicity and $\mathrm{IC}_{50}$ of pure clausenidin in HT-29 cells. Clausenidin induced cytotoxic effects in HT-29 cells in a dose dependent manner (Fig. 2). The $\mathrm{IC}_{50}$ of clausenidin obtained after treating the cells for $72 \mathrm{~h}$ is $13.8 \pm 2.89 \mu \mathrm{g} / \mathrm{mL}$ while that of doxorubicin is $6.2 \pm 0.14 \mu \mathrm{g} / \mathrm{mL}$.

\section{Fluorescent microscopy}

The fluorescent microscopy was performed after staining the clausenidin-treated cells with equal proportions of acridine orange and propidium iodide dyes. The fluorescent micrograph reveals the apoptosis inducing effects of clausenidin in HT-29 cells (Fig. 3). Some of the morphological aberrations observed includes membrane blebbing and chromatin condensation which are early

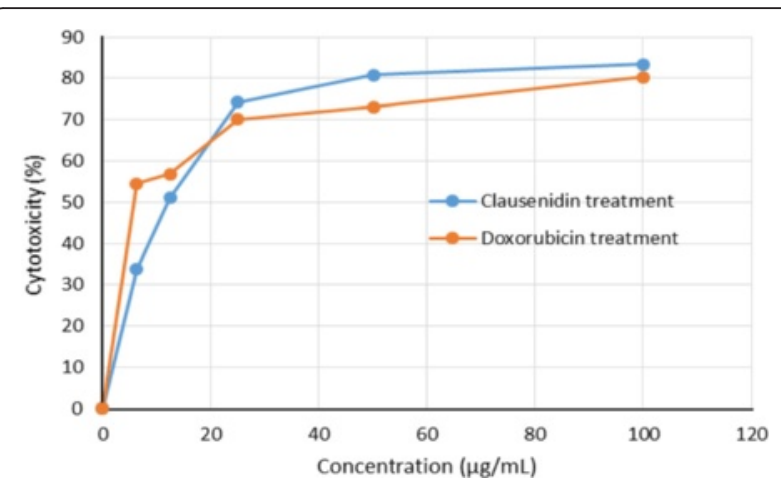

Fig. 2 Cytotoxicity of HT-29 cells treated with clausenidin and doxorubicin. The $I C_{50}$ of clausenidin and doxorubicin is $13.80 \pm 2.89$ and $6.20 \pm 0.14 \mu \mathrm{g} / \mathrm{mL}$, respectively

signs of apoptosis (Figs. 3b - d). In addition some cells were observed to be undergoing secondary necrosis.

\section{Transmission electron microscopy}

To further confirm the occurrence of apoptosis, the ultrastructural micrograph of clausenidin treated HT-29 cells were monitored in a time dependent manner and it revealed the presence of nuclei shrinkage and fragmentation, chromatin condensation, lipid droplets and convolution of nuclei outline which are hallmarks of apoptosis (Fig. 4). An increase in vacuolation and loss of microvilli was observed as the treatment time increased.

\section{ROS production assay}

The production of ROS in HT-29 cells was measured using flow cytometry in the FITC channel. The assay method employed identified only cells that are actively producing the intracellular ROS. The result in Fig. 5 shows that the percentage (\%) of HT-29 cells producing ROS increased significantly $(p<0.05)$ after treatment with clausenidin at $24 \mathrm{~h}$ compared to the untreated cells. However, a decline was observed at 48 and $72 \mathrm{~h}$ compared to that of $24 \mathrm{~h}$ because the active ROS producing

Table 1 Gene name and sequences of primers used in the multiplex panel

\begin{tabular}{lll}
\hline Gene Name & Forward sequence & Reverse sequence \\
\hline Bax & AGGTGACACTATAGAATAGCAAACTGGTGCTCAA & GTACGACTCACTATAGGGAAACCACCCTGGTCTTG \\
Bcl-2 & AGGTGACACTATAGAATACTGTGGATGACTGAGTACCT & GTACGACTCACTATAGGGATCAGAGACAGCCAGGAG \\
Apaf-1 & AGGTGACACTATAGAATACATACTCTITCACCAGATCA & GTACGACTCACTATAGGGAACAAGTTCTGTITTGCTIT \\
Cyt c & AGGTGACACTATAGAATAGAGCGAGTTGGTTGC 3 & GTACGACTCACTATAGGGAAATCTTCTTGCCTITCTC \\
Caspase 9 & AGGTGACACTATAGAATATGTAGAAGAGTTCGTGAGT & GTACGACTCACTATAGGGAGAGTTTCAGTGTTCTCCAT \\
B-actin & AGGTGACACTATAGAATAGCTGGTGGAAGAGCTG & GTACGACTCACTATAGGGACTCTAAGCAGGAGATGAACA \\
\hline
\end{tabular}

The $\beta$-actin gene was used for normalization. Reverse transcription (RT) and PCR were done according to manufacturer's instructions; RT reaction was at $480{ }^{\circ} \mathrm{C}$ for $1 \mathrm{~min} ; 370^{\circ} \mathrm{C}$ for $5 \mathrm{~min} ; 420^{\circ} \mathrm{C}$ for $60 \mathrm{~min} ; 950^{\circ} \mathrm{C}$ for $5 \mathrm{~min}$; then held at $40^{\circ} \mathrm{C}$, while PCR was as follows: initial denaturation at $950{ }^{\circ} \mathrm{C}$ for $10 \mathrm{~min}$, followed by two-step cycles of $940{ }^{\circ} \mathrm{C}$ for $30 \mathrm{~s}$ and $550^{\circ} \mathrm{C}$ for $30 \mathrm{~s}$, ending in a single extension cycle of $680^{\circ} \mathrm{C}$ for $1 \mathrm{~min}$. Bax: BCl-2-associated X protein; Bcl-2: B cell lymphoma 2; Apaf-1: Apoptotic protease activating factor 1; Cyt c: cytochrome complex; Caspase 3: Cysteine aspartic acid protease 3; Caspase 9: Cysteine aspartic acid protease 9 

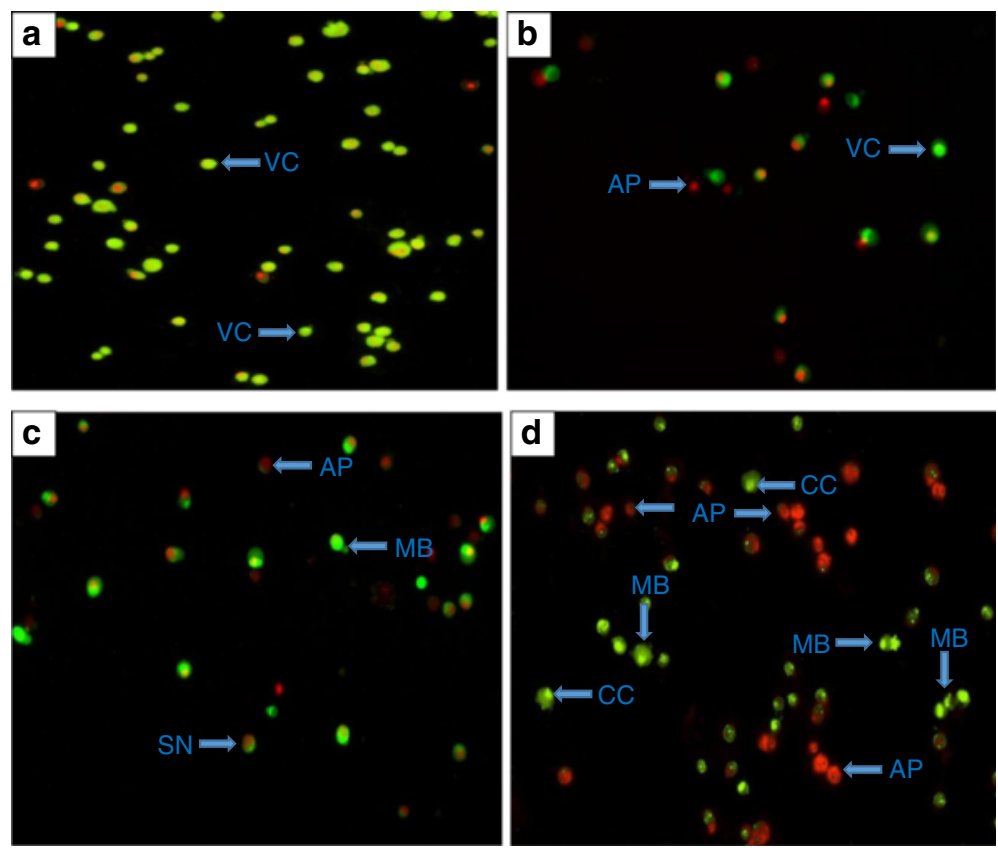

Fig. 3 Acridine orange and propidium iodide-stained clausenidin-treated HT-29 cells. b, c, d are treatments with 5, 15, and $30 \mu \mathrm{g} / \mathrm{mL}$ clausenidin, respectively and (a) is the untreated control. VC - Viable cells, AP - apoptosis, MB - membrane blebbing, SN - necrosis. Analyses in triplicates. * Significant difference between means at $p<0.05$

cells were dying due to the oxidative stress (Fig. 5c and d). Conversely, the percentage of the non-active ROS producing cells in the treatments decreased significantly $(p<0.05)$ as the treatment time progressed. This is due to stimulating effect of clausenidin which caused the more cells to begin the production of ROS.

\section{DNA fragmentation analysis}

The HT-29 cells were treated with clausenidin $(13.8 \mu \mathrm{g} / \mathrm{mL})$ at $12 \mathrm{~h}$ and $24 \mathrm{~h}$ which led to the generation of DNA fragments shown in the gel image (Fig. 6). The untreated cells (negative control) had their genomic DNA intact with no fragments generated (lane $C$ ) unlike the treatments (lanes A \& B) and positive control (lane D). Clausenidin induced an internucleosomal cleavage of DNA in HT-29 cells leading to the generation of fragments which is a basic feature of apoptosis [24, 25].

\section{Cell cycle analysis}

The DNA content histograms of HT-29 cells treated with clausenidin is shown in Fig. 7 which suggests a G0/ G1 phase arrest. The percentage cell distribution (Fig. 7e) further reveals that clausenidin induces a G0/G1 phase arrest in HT-29 cells. The percentage of apoptotic cells (sub G0/G1) increased significantly $(p<0.05)$ compared to the control as treatment time progressed to $72 \mathrm{~h}$ (Fig. 7e) as a result of the cytotoxic effects of clausenidin.

\section{Annexin V Assay}

The occurrence of apoptosis was further corroborated using the annexin $\mathrm{V}$ and PI staining assay because annexin $\mathrm{V}$ is able to bind membrane phospholipid which is released prior to the loss of membrane integrity. The annexin V assay distinguished between HT-29 cells in early and late apoptotic state after exposure to clausenidin (Fig. 8). Overall, the result in Fig. 8 shows a significant increase $(p<0.05)$ in the percentage of apoptotic cells resulting from clausenidin treatment in a time dependent manner compared to the untreated cells.

\section{MMP Assay}

The MMP assay was done to assess the mitochondrial function, since it is an organelle that is intimately involved in reception of signals that culminates in apoptosis. The MMP results shows a significant increase $(p<$ $0.05)$ in collapse of MMP (green fluorescence) while a concomitant significant decrease $(p<0.05)$ was observed in the percentage of live cells with intact mitochondria (red fluorescence) (Fig. 9). The green fluorescence is as a result of increasing membrane depolarization while red fluorescence is a reflection of high membrane polarization after staining with the JC-1 dye.

\section{Caspases 3 \& 9}

Caspase 9 is an initiator caspase whose function enables the activation of executioner caspases such as caspase 3 [26]. The result in Fig. 10 shows clausenidin induces a 

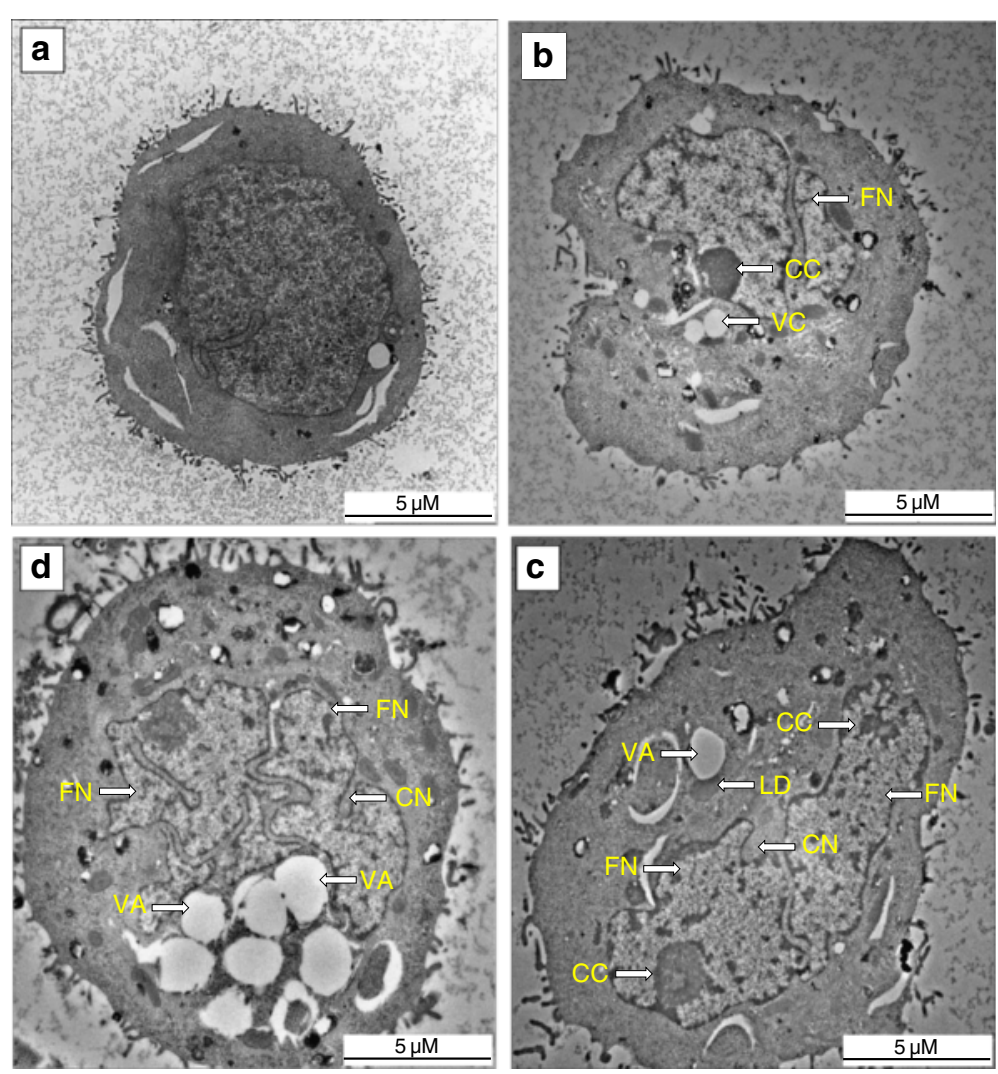

Fig. 4 Ultrastructural assessment of clausenidin-treated HT-29cells. b, c, d are treatments ( $13.8 \mu \mathrm{g} / \mathrm{mL})$ for $24 \mathrm{~h}, 48 \mathrm{~h}$, and $72 \mathrm{~h}$ respectively and (a) is the untreated control. VA - vacuole; LD - lipid droplet; FN - fragmented nucleus; CC - chromatin condensation; CN - convolution of nuclear outline. Analyses in triplicates

significant increase $(p<0.05)$ in the expression of caspases 3 and 9 in HT-29 cells in a dose dependent manner.

\section{Gene expression studies}

The gene expression studies was conducted to gain possible insights on how clausenidin affects the expression of caspases genes and other apoptotic genes associated

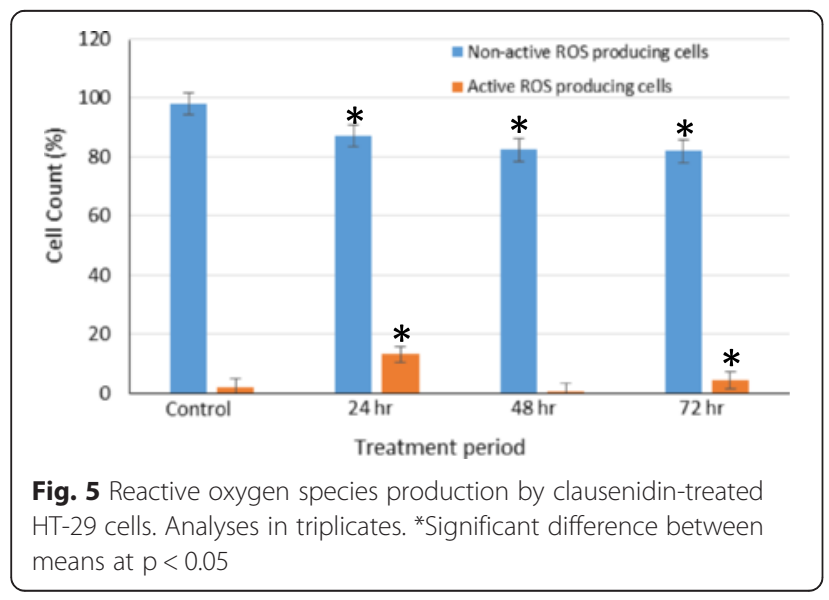

with the mitochondrial pathway of apoptosis. The results shows that clausenidin significantly increases $(p<0.05)$ the expression of caspases 3 and 9 genes at 12 and $24 \mathrm{~h}$ of treatment (Fig. 11). Similarly, the expressions of Cyt c, Apaf-1, and Bax were significantly increased after $24 \mathrm{~h}$

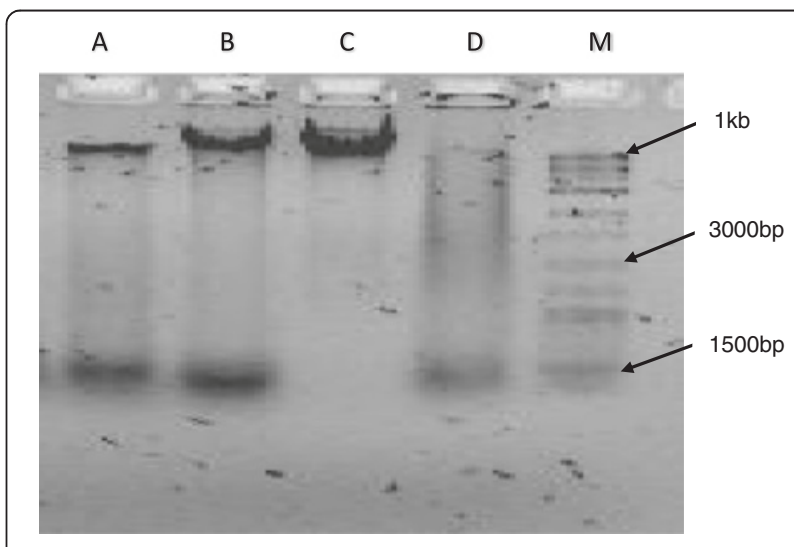

Fig. 6 DNA fragmentation in clausenidin-treated HT-29 cells. A and B are treatments $(13.8 \mu \mathrm{g} / \mathrm{mL})$ for $12 \mathrm{~h}$ and $24 \mathrm{~h}$ respectively, $D$ is positive control supplied with the kit while $C$ is the untreated control. $\mathrm{M}$ is the molecular marker. Analysis in triplicates 

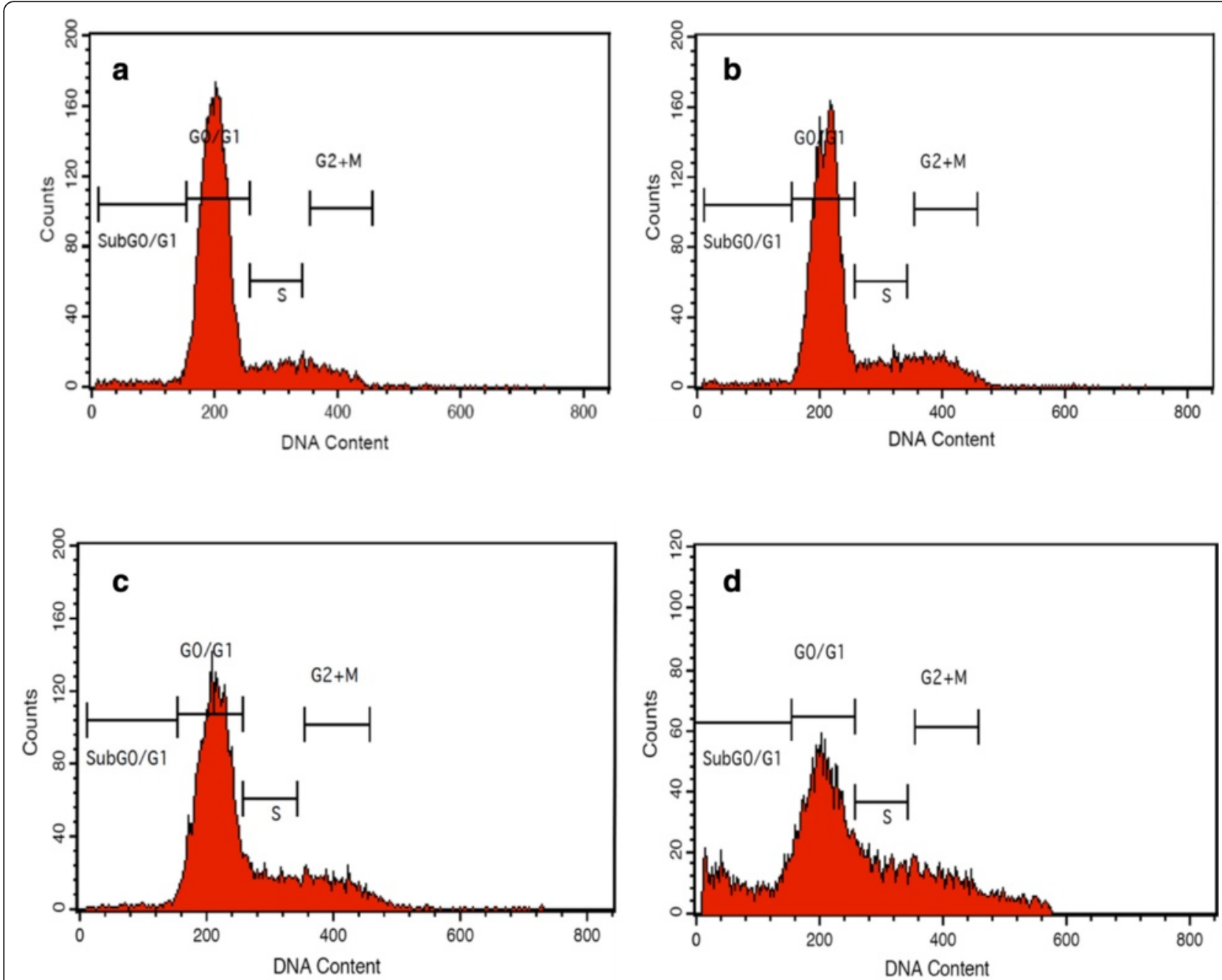

e

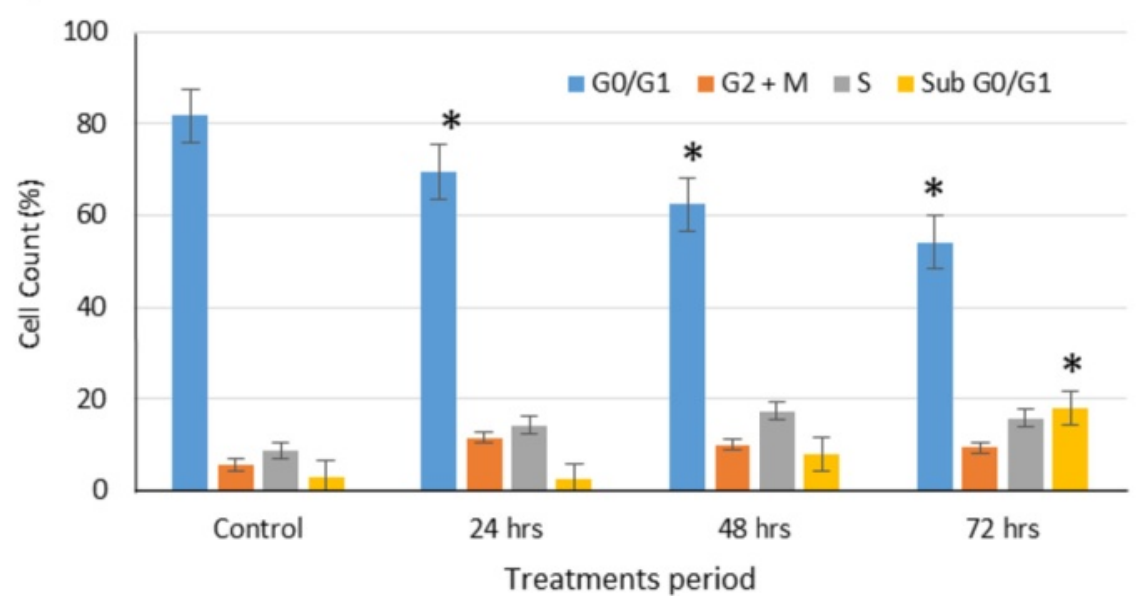

Fig. 7 Cell cycle of clausenidin-treated HT-29 cells. b, c, d are DNA contents of cell treated for 24, 48, 72 h, respectively and (a) is untreated control cells. e represents \% cell count at cell cycle phases. Analyses in triplicates. (*Significant difference between means at $p<0.05$ ) 

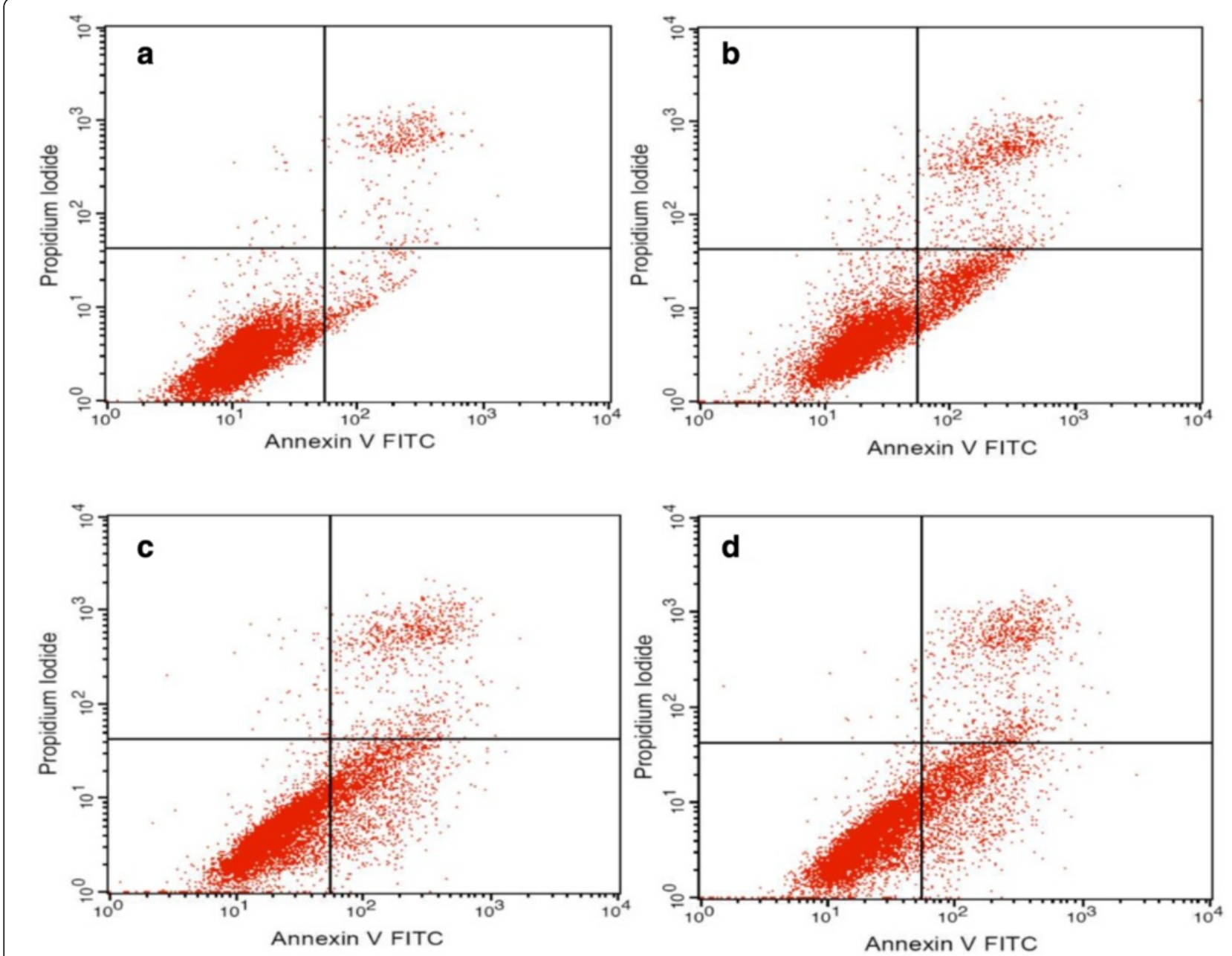

e

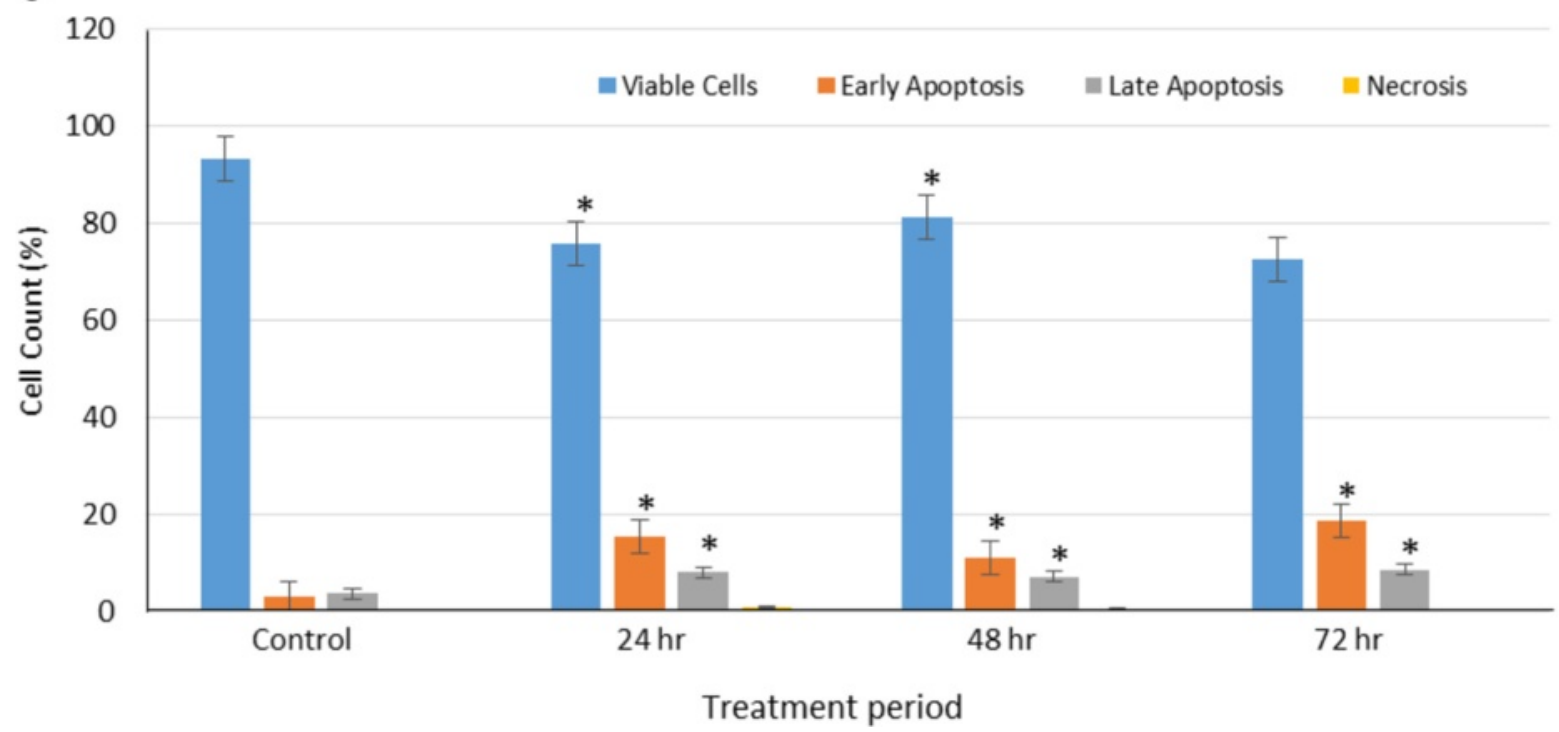

Fig. 8 Annexin V assay of clausenidin-treated HT-29 cells. b, c, d represent viable and dead cells after treatment for $24,48,72$ h, respectively and (a) is untreated control cells. e represents \% cell count. Analyses in triplicates. ( ${ }^{*}$ Significant difference between means at $p<0.05$ ) 

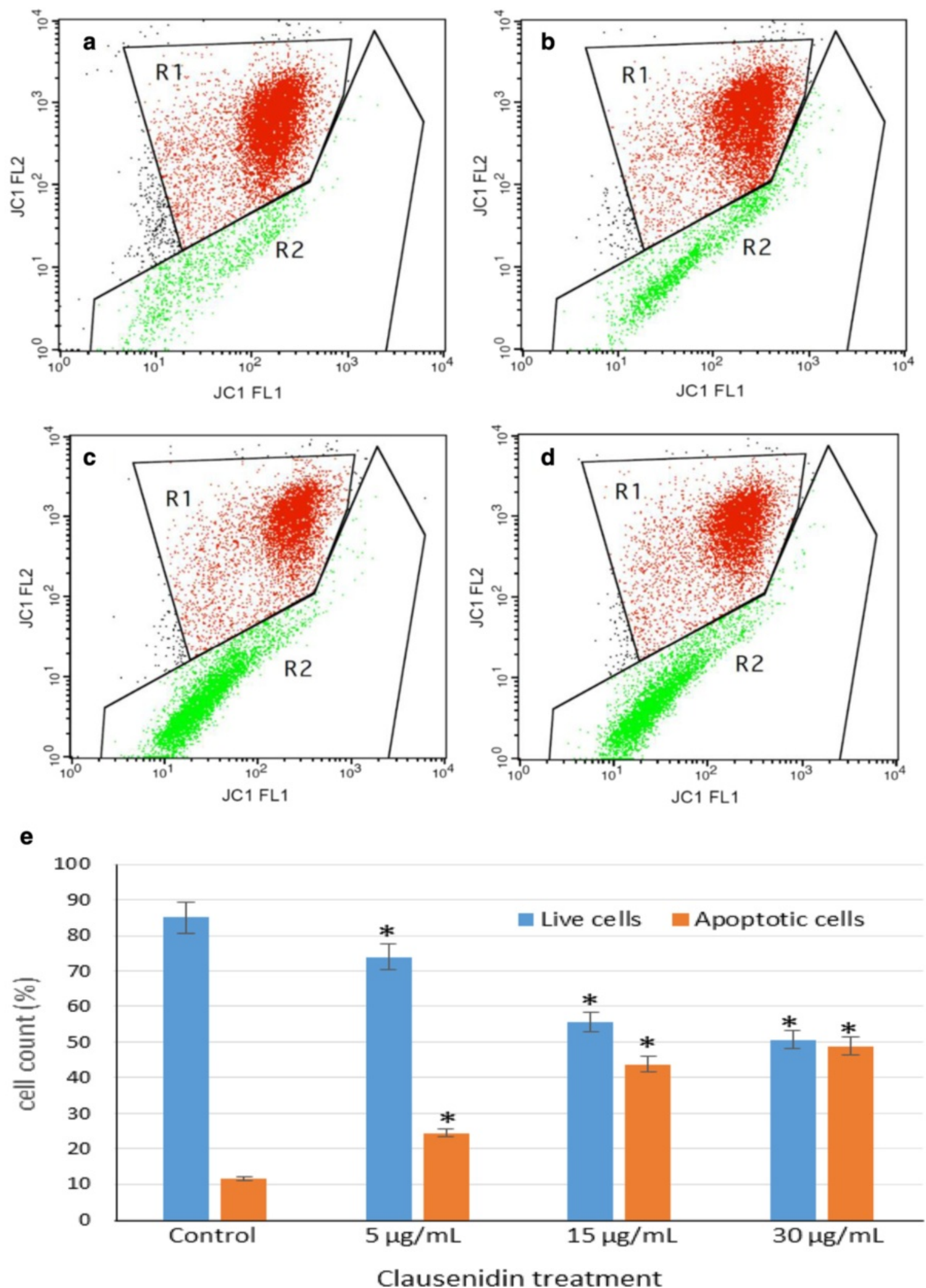

Fig. 9 Mitochondrial membrane potential assay of clausenidin-treated HT-29cells. b, c, d represent treatment with 5, 15, and $30 \mu \mathrm{g} / \mathrm{mL}$ clausenidin respectively and (a) is the untreated control. Red fluorescence: cells with intact mitochondria, green fluorescence: cells with depolarized mitochondrial membrane. e represents proportion of live and apoptotic cells. Analyses in triplicates. (*Significant difference between means at $p<0.05$ ) 


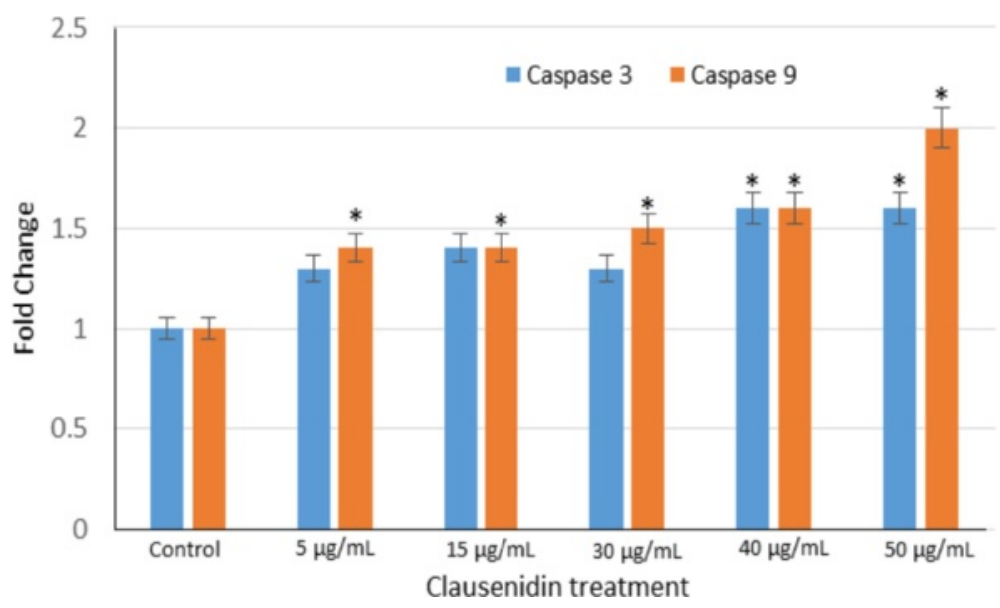

Fig. 10 Caspase activities in clausenidin-treated HT-29 cells. Analyses in triplicates. ( ${ }^{*}$ Significant difference between means at $p<0.05$ )

of treatment with clausenidin compared to the untreated cells.

\section{Discussion}

There are few literatures on the isolation of clausenidin and its potential cytotoxic effects but none of the reports have clearly defined the mechanism of action of clausenidin in any cancer cell line. In this particular study, we investigated the cascade of reactions that triggers apoptosis in HT-29 cells treated with clausenidin from Clausena excavata. It was observed that apoptosis occurred in the clausenidin treated HT29 cells via caspase 9 mediated signaling.

The purified clausenidin induced cytotoxic effects in HT-29 cells in a dose dependent manner with an $\mathrm{IC}_{50}$ of $13.8 \pm 2.89 \mu \mathrm{g} / \mathrm{mL}$. This could be a justification for the wide usage of $C$ excavata in Asian folk medicine. Apoptosis is programmed active cell death. A number of anticancer drugs have been screened and selected based on their abilities to initiate the physiological events that culminates in cell death [7]. We observed the presence of membrane blebs, and chromatin condensation in the fluorescent micrographs of clausenidin treated HT-29 cells which represents features of incipient apoptosis [27]. Similarly, the ultrastructural micrograph revealed morphological aberrations within the organelles in HT29 cells associated with apoptosis. The apoptotic features observed includes appearance of lipid droplets (as a result of cell membrane damage), condensation of chromatin and nuclear fragmentation which further corroborated apoptosis in the clausenidin treated HT-29 cells.

DNA fragmentation and loss of mitochondrial membrane integrity precedes apoptosis [8]. Clausenidin caused a nucleosomal DNA cleavage in HT-29 cells which led to the generation of DNA fragments as shown earlier in the gel image result. The generation of DNA fragments increased as the treatment time progressed suggesting the ability of clausenidin to sustain apoptosis in HT-29 cells. As a proof of the apoptosis-inducing

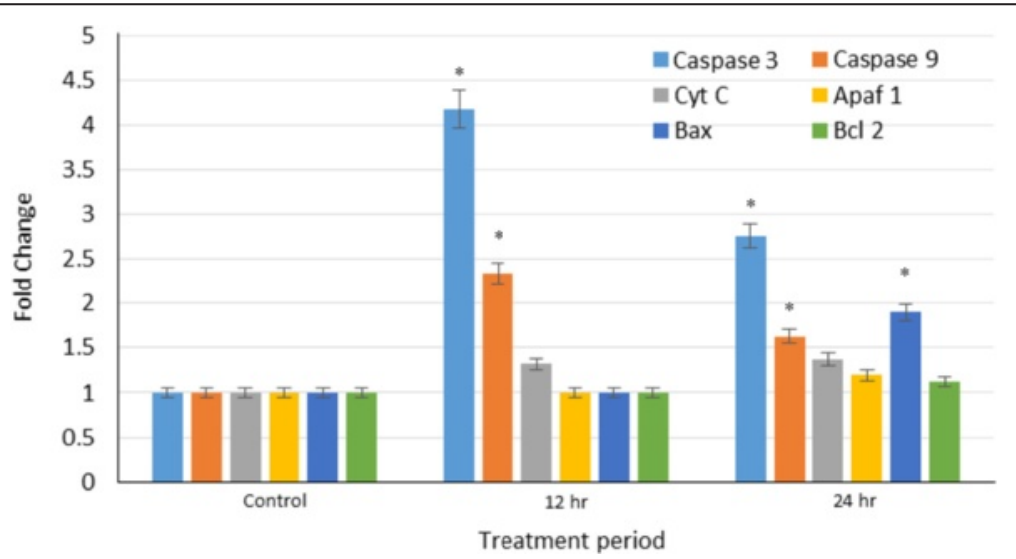

Fig. 11 Caspase, Cyt C, Apaf 1, Bax and Bcl2 gene expressions in clausenidin-treated HT-29 cells. Analyses in triplicates. (*Significant difference between means at $p<0.05$ ) 
effect of clausenidin, we observed a loss of MMP in the HT-29 cells which is a prerequisite for apoptosis to occur via the mitochondrial pathway. Also, apoptosis induced by some chemotherapeutic agents is controlled by the ratio of bax:bcl 2 expressions in the mitochondria [28]. Increased expression of Bax is known to stimulate a collapse of MMP which terminates in apoptosis [29]. Our gene expression study result shows a significant increase $(p<0.05)$ in the bax level which could have triggered the MMP collapse in clausenidin treated HT-29 cells observed earlier. In addition, a significant increase $(p<0.05)$ in cytochrome $\mathrm{c}$ and Apaf-1 genes expression were observed after treatment with clausenidin. Mitochondrial release of cytochrome $\mathrm{c}$ into the cytoplasm enables it to interact with AATP and Apaf-1 to form the apoptosome complex and subsequent activation of caspases [26]. The mitochondria has been described as a major component of the intrinsic pathway because of its ability to activate the apoptosis program directly. Therefore, we suspect that the increased levels of the apoptotic genes as observed in this study could have been triggered by clausenidin induced mitochondrial signaling. In a recent study with dentatin isolated also from $C$. excavata, it was observed that apoptosis occurred via mitochondrial pathway signaling in the dentatin-treated MCF-7 breast cancer cells [21].

Moreover, the expressions of caspases 3 and 9 proteins increased significantly $(p<0.05)$ after treating the HT-29 cells with clausenidin. Caspase 9 is a key regulator of mitochondrial apoptosis, because it functions as a gatekeeper of the intrinsic pathway [11]. So therefore, an increase in the expression of caspase 9 protein and gene as observed in this study strongly suggests the involvement of the intrinsic pathway (mitochondrial pathway) in the induction of apoptosis in clausenidin-treated HT-29 cells. Impaired functions of the caspase 9 promoter or caspase 9 gene which leads to low activity of caspase 9 has been implicated as a cause of various cancers such as colon cancer [30-33]. We observed that clausenidin treatment significantly increased $(p<0.05)$ the expression of caspase 9 gene by over two (2) folds. It is no surprise that the caspase 3 expression also increased significantly since it depends on caspase 9 for activation [11]. Caspase 3 executes apoptosis via selective destruction of subcellular structures, organelles or even the genome [11]. Our earlier results of TEM and DNA fragmentation analysis confirms this process of subcellular destruction. An increased expression of caspases 3 and 9 have also been reported in breast cancer cells treated with dentatin isolated from C. excavata [21].

One of the mechanisms by which anticancer agents induce apoptosis is through the creation of oxidative imbalance, which is a consequence of increased intracellular ROS production beyond the capacity of antioxidant defense system [34]. Previous studies have shown that there is a relationship between the mitochondrial derived ROS and the activation of caspases [35, 36]. The increased production of ROS in the present study could have triggered the clausenidin induced apoptosis in HT-29 cells as shown by our TEM micrographs. ROS has been reported to cause DNA strand cleavage as well as cell membrane injury [34] which we observed in the present study.

However, insensitivity to growth inhibitory signals has been proposed as one of the hallmarks of cancer survival strategy [11]. This leads to an inability to regulate the cell cycle which culminates in the development of cancer [37]. The cell cycle result shows that clausenidin induces a G0/G1 arrest in HT-29 cells. This finding could suggest another pathway through which clausenidin elicits signals that inhibits/controls the growth of tumor cells. Another vital observation in the cell cycle assay is the significant increase in the fractionated DNA of the clausenidin treated cells as represented by the sub G0/G1 fraction. This important finding and other results presented in this study lends credence to the occurrence of apoptosis in the clausenidin treated HT-29 cells.

\section{Conclusion}

Apoptosis was induced successfully in colon cancer cells using clausenidin isolated from $C$. excavata. The clausenidin-stimulated apoptosis occurred via increased expressions of caspases 3 and 9. In addition, the current study justifies claims of anti-tumor properties of Clausena excavata Burm. $f$. in the traditional treatment of malignant cancers.

\section{Abbreviations \\ Apaf-1, Apoptotic protease activating factor-1; Bax, BCl 2 associated $\mathrm{x}$ protein: BCl 2, B cell lymphoma 2; Caspase, cysteine aspartic acid protease; Cyt c, Cytochrome complex; DMEM, Dulbecco's Modified Eagle's Medium; DMSO, Dimethyl sulfoxide; DNA, Deoxyribonucleic acid; HT-29 cells, Colon cancer cells; MTT, 3-(4,5-dimethylthiazol-2-yl)-2,5-Diphenyltetrazolium bromide; qPCR, quantitative Polymerase Chain reaction; ROS, Reactive oxygen species; TEM, Transmission electron microscopy.}

\section{Acknowledgements \\ The authors' wish to thank Prof Rosita Rosli the entire staff of Makna-Cancer research Laboratory, University Putra Malaysia for their support during the course of this project. \\ Funding \\ This project was funded by Science Fund Research Grant (02-01-04-SF1210), Ministry of Science, Technology and Innovation, Malaysia.}

Availability of data and materials

All data are contained within the paper.

\section{Authors' contribution}

All authors listed contributed to the design and conduct of the experiments reported in this manuscript. They have also read and approved the

submission of the manuscript.

Competing interests

The authors declare that they have no competing interests. 


\section{Consent for publication}

Not applicable.

\section{Ethics approval and consent to participate}

Not applicable.

\section{Author details}

MAKNA Cancer Research Laboratory, Institute of Bioscience, University Putra Malaysia, Serdang, Selangor, Malaysia. ${ }^{2}$ Department of Biochemistry, Kaduna State University, Main Campus, PMB 2336 Kaduna, Nigeria. ${ }^{3}$ Department of Veterinary Pathology and Microbiology, Faculty of Veterinary Medicine, University Putra Malaysia, Serdang, Selangor, Malaysia. ${ }^{4}$ Laboratory of Vaccine and Therapeutics, Institute of Bioscience, University Putra Malaysia, Serdang, Selangor, Malaysia. ${ }^{5}$ Department of Chemistry, Faculty of Science, University Putra Malaysia, Serdang, Selangor, Malaysia. "Enzyme Technology Research Laboratory, Institute of Bioscience, University Putra Malaysia, Serdang, Selangor, Malaysia.

Received: 18 March 2016 Accepted: 23 July 2016

Published online: 29 July 2016

\section{References}

1. Terzić J, Grivennikov S, Karin E, Karin M. Inflammation and colon cancer. Gastroenterol. 2010;138(6):2101-2114. e2105.

2. Twelves C, Wong A, Nowacki MP, Abt M, Burris III H, Carrato A, Cassidy J, Cervantes A, Fagerberg J, Georgoulias V. Capecitabine as adjuvant treatment for stage III colon cancer. Engl J Med. 2005;352(26):2696-704.

3. Jemal A, Center MM, DeSantis C, Ward EM. Global patterns of cancer incidence and mortality rates and trends. Cancer Epidemiol Biomark Prev. 2010;19(8):1893-907.

4. Vander Heiden MG, Cantley LC, Thompson CB. Understanding the Warburg effect: the metabolic requirements of cell proliferation. Science. 2009; 324(5930):1029-33

5. Jones NP, Schulze A. Targeting cancer metabolism-aiming at a tumour's sweet-spot. Drug Discov Today. 2012;17(5):232-41.

6. Haller DG, Tabernero J, Maroun J, de Braud F, Price T, Van Cutsem E, Hill M, Gilberg F, Rittweger K, Schmoll H-J. Capecitabine plus oxaliplatin compared with fluorouracil and folinic acid as adjuvant therapy for stage III colon cancer. J Clin Oncol. 2011;29(11):1465-71.

7. Fesik SW. Promoting apoptosis as a strategy for cancer drug discovery. Nat Rev Cancer. 2005;5(11):876-85.

8. Majno G, Joris I. Apoptosis, oncosis, and necrosis. An overview of cell death. Am J Pathol. 1995:146(1):3.

9. Hakem R, Hakem A, Duncan GS, Henderson JT, Woo M, Soengas MS, Elia A, de la Pompa JL, Kagi D, Khoo W. Differential requirement for caspase 9 in apoptotic pathways in vivo. Cell. 1998;94(3):339-52.

10. Varfolomeev EE, Schuchmann M, Luria V, Chiannilkulchai N, Beckmann JS, Mett IL, Rebrikov D, Brodianski VM, Kemper OC, Kollet O. Targeted disruption of the mouse Caspase 8 gene ablates cell death induction by the TNF receptors, Fas/Apo1, and DR3 and is lethal prenatally. Immunity. 1998; 9(2):267-76.

11. Hanahan D, Weinberg RA. The hallmarks of cancer. Cell. 2000;100(1):57-70

12. Fleischer A, Ghadiri A, Dessauge F, Duhamel M, Rebollo MP, Alvarez-Franco F, Rebollo A. Modulating apoptosis as a target for effective therapy. Mol Immunol. 2006;43(8):1065-79.

13. Nagata S. Apoptotic DNA fragmentation. Exp Cell Res. 2000:256(1):12-8.

14. Hector S, Rehm M, Schmid J, Kehoe J, McCawley N, Dicker P, Murray F, McNamara D, Kay EW, Concannon CG. Clinical application of a systems model of apoptosis execution for the prediction of colorectal cancer therapy responses and personalisation of therapy. Gut. 2012;61(5):725-33.

15. Amin F, Bowen ID, Szegedi Z, Mihalik R, Szende B. Apoptotic and nonapoptotic modes of programmed cell death in MCF-7 human breast carcinoma cells. Cell Biol Int. 2000;24(4):253-60.

16. Huang S-C, Wu P-L, Wu T-S. Two coumarins from the root bark of Clausena excavata. Phytochemistry. 1997;44(1):179-81.

17. Manosroi A, Saraphanchotiwitthaya A, Manosroi J. Immunomodulatory activities of fractions from hot aqueous extract of wood from Clausena excavata. Fitoterapia. 2004;75(3):302-8.

18. Wu T-S, Furukawa H. Biological and phytochemical investigation of Clausena excavata. J Nat Prod. 1982;45(6):718-20.
19. Takemura Y, Nakamura K, Hirusawa T, Ju-Ichi M, Ito C, Furukawa H. Four new furanone-coumarins from Clausena excavata. Chem Pharm Bull. 2000;48(4):582-4.

20. Su C-R, Yeh SF, Liu CM, Damu AG, Kuo T-H, Chiang P-C, Bastow KF, Lee K-H, Wu T-S. Anti-HBV and cytotoxic activities of pyranocoumarin derivatives. Bioorg Med Chem. 2009;17(16):6137-43.

21. Arbab IA, Abdul AB, Sukari MA, Abdullah R, Syam S, Kamalidehghan B, Ibrahim MY, Taha MME, Abdelwahab SI, Ali HM. Dentatin isolated from Clausena excavata induces apoptosis in MCF-7 cells through the intrinsic pathway with involvement of NF-kB signalling and G0/G1 cell cycle arrest: a bioassay-quided approach. J Ethnopharmacol. 2013;145(1):343-54.

22. Syama S, Bustamama A, Abdullahb R, Sukaric MA, Hashimd NM, Ghaderiand M, Rahmanic M, Mohane S, Abdelwahabe SI. Alif HM: b-Mangostin induces p53-dependent G2/M cell cycle arrest and apoptosis through ROS mediated mitochondrial pathway and NfkB suppression in MCF-7 cells. 2013.

23. Tan M, Muhammad TT, Najimudin N, Sulaiman S. Growth arrest and nonapoptotic programmed cell death associated with the up-regulation of c-myc mRNA expression in T-47D breast tumor cells following exposure to Epipremnum pinnatum (L.) Engl. hexane extract. J Ethnopharmacol. 2005:96(3):375-83.

24. Earnshaw WC. Nuclear changes in apoptosis. Curr Opin Cell Biol. 1995;7(3): 337-43.

25. Wyllie AH. Glucocorticoid-induced thymocyte apoptosis is associated with endogenous endonuclease activation. 1980

26. Marsden VS, O'Connor L, O'Reilly LA, Silke J, Metcalf D, Ekert PG, Huang DC, Cecconi F, Kuida K, Tomaselli KJ. Apoptosis initiated by Bcl-2-regulated caspase activation independently of the cytochrome c/Apaf-1/caspase-9 apoptosome. Nature. 2002;419(6907):634-7.

27. Mohan S, Abdul AB, Abdelwahab SI, Al-Zubairi AS, Sukari MA, Abdullah R, Taha MME, Ibrahim MY, Syam S. Typhonium flagelliforme induces apoptosis in CEMss cells via activation of caspase-9, PARP cleavage and cytochrome c release: Its activation coupled with G0/G1 phase cell cycle arrest. J Ethnopharmacol. 2010; 131(3):592-600.

28. Korsmeyer SJ, Shutter JR, Veis DJ, Merry DE, Oltvai ZN. BCl-2/Bax: a rheostat that regulates an anti-oxidant pathway and cell death. Semin Cancer Biol. 1993;1993:327-32

29. Zamzami N, Kroemer G. Apoptosis: mitochondrial membrane permeabilization-the (w) hole story? Curr Biol. 2003;13(2):R71-3.

30. Gangwar R, Mandhani A, Mittal RD. Caspase 9 and caspase 8 gene polymorphisms and susceptibility to bladder cancer in north Indian population. Ann Surg Oncol. 2009;16(7):2028-34.

31. Theodoropoulos GE, Gazouli M, Vaiopoulou A, Leandrou M, Nikouli S, Vassou E, Kouraklis G, Nikiteas N. Polymorphisms of caspase 8 and caspase 9 gene and colorectal cancer susceptibility and prognosis. Int J Colorectal Dis. 2011;26(9):1113-8

32. Liamarkopoulos E, Gazouli M, Aravantinos G, Tzanakis N, Theodoropoulos G Rizos S, Nikiteas N. Caspase 8 and caspase 9 gene polymorphisms and susceptibility to gastric cancer. Gastric Cancer. 2011;14(4):317-21.

33. Park JY, Park JM, Jang JS, Choi JE, Kim KM, Cha SI, Kim CH, Kang YM, Lee WK, Kam S. Caspase 9 promoter polymorphisms and risk of primary lung cancer. Hum Mol Genet. 2006;15(12):1963-71.

34. Avendaño C, Menendez JC: Medicinal chemistry of anticancer drugs. Hungary: Elsevier; 2015. pp. 95-100

35. Simon H-U, Haj-Yehia A, Levi-Schaffer F. Role of reactive oxygen species (ROS) in apoptosis induction. Apoptosis. 2000;5(5):415-8.

36. Skulachev VP. Why are mitochondria involved in apoptosis? Permeability transition pores and apoptosis as selective mechanisms to eliminate superoxide-producing mitochondria and cell. FEBS Lett. 1996;397(1):7-10.

37. Hartwell LH, Kastan MB. Cell cycle control and cancer. Science. 1994 266(5192):1821-8. 